\title{
Engine Control simulation Research of DRM-PCS
}

\author{
Kejun Jiang ${ }^{1,2, a}$, Ren $\mathrm{He}^{2, b}$, Yan Zhang ${ }^{1, c}$, and Kuiyang Wang ${ }^{1, \mathrm{~d}}$
}

1.School of Automobile and Traffic Engineering, Jiangsu University of Technology, Changzhou
213001, Jiangsu, China

2. School of Automobile and Traffic Engineering, Jiangsu University, Zhenjiang, 212013, China

ajxjkj@jstu.edu.cn, bheren@ujs.edu.cn, 'cczhangyan@ jstu.edu.cn, dwangkuiyang@jstu.edu.cn

Keywords: hybrid electric vehicle, Double Rotor Motor Power Coupling System(DRMPCS), engine, optimal operation point control

\begin{abstract}
Double Rotor Motor Power Coupling System (DRM-PCS), as a new kind of power coupling system, can be used in hybrid electric vehicle to make the engine operate efficiently by decoupling the engine speed from the wheels. In this paper, the thought and method of the engine optimal control are put forward. With the help of the data fitting method and the steepest descent algorithm, the optimal operation point of the engine is calculated. Then using the fuzzy control method, the simulation model of the engine optimal operation point controller is established. The simulation results show the controller can make the effective adjustments to the engine operation, and the control performance on the engine fuel consumption rate is better. In addition, the simulation results suggest that the optimization time of the control method has obvious influence on the stability of the DRM-PCS in the hybrid driving mode with low speed.
\end{abstract}

\section{Introduction}

Double Rotor Motor Power Coupling System (DRM-PCS) is a new type of hybrid coupling system[1]. From Figure 1, we can know the structure of the DRM-PCS. The DRM-PCS belongs to the non-contact electromagnetic power coupling system. This type of coupling system has the advantages of simple structure, easy maintenance, and zero wear. So it is suitable for hybrid electric vehicle, and nowadays has become a new approach to develop the power coupling technology for hybrid electric vehicle[2,3].

In the DRM-PCS, because of no mechanical connection between engine's crankshaft and the subsequent transmission shaft, the engine can work with more freedom. This is the fundamental reason for the system to have optimal fuel economy, and it also put forward higher requirements to engine control.

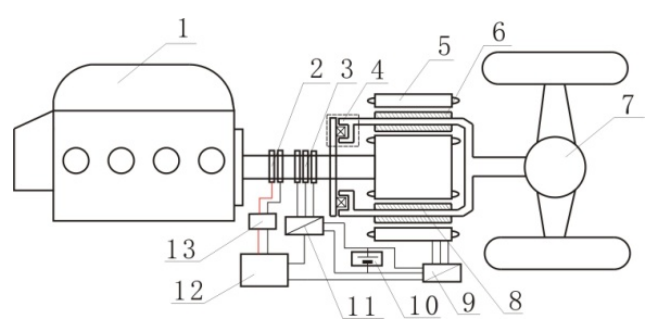

1-engine 2- power slip ring of electromagnetic synchronizer 3- power slip ring of inner rotor 4- electromagnetic synchronizer 5- stator coil 6- outer permanent magnet of outer rotor 7-drive axle 8- inner permanent magnet of outer rotor 9-convert of outer motor 10-battery 11-conert of inner motor 12-control unit 13- driving amplifier

Fig.1 Structure diagram of the DRM-PCS

\section{The Optimal operation Point of Engine}

Figure 2 is the universal performance characteristic map of a certain four cylinder petrol engine. According to the calculation, we can identify the optimal operation area, its load torque range is 65 - $83 \mathrm{~N} \cdot \mathrm{m}$, and its speed range is 1800-3700 RPM.According to the engine fuel consumption data from Figure 2, we can get the fuel consumption curved surface of the engine using the Matlab 
software (as shown in Figure 3). Using the Polynomial method to fit the curved surface with higher power[4], we get the mathematical model of engine fuel consumption characteristic, which can be expressed by formula (1).

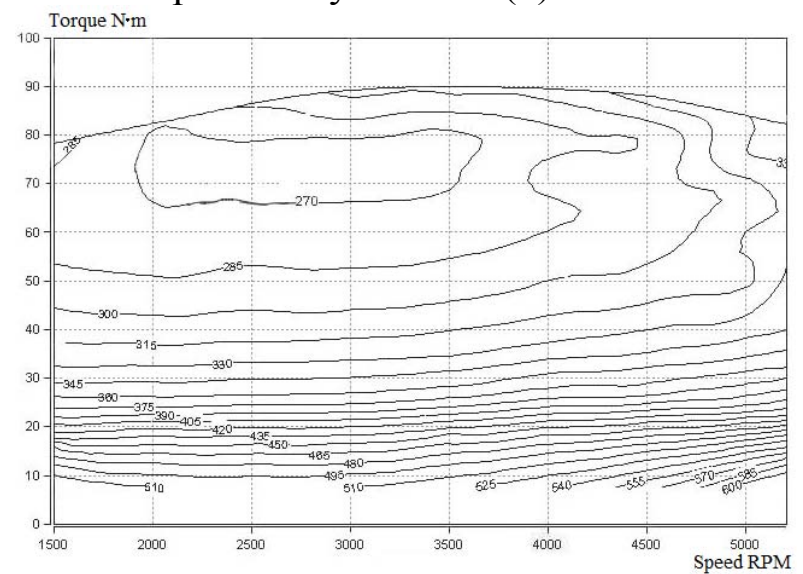

Fig.2 Universal performance characteristic map of the engine

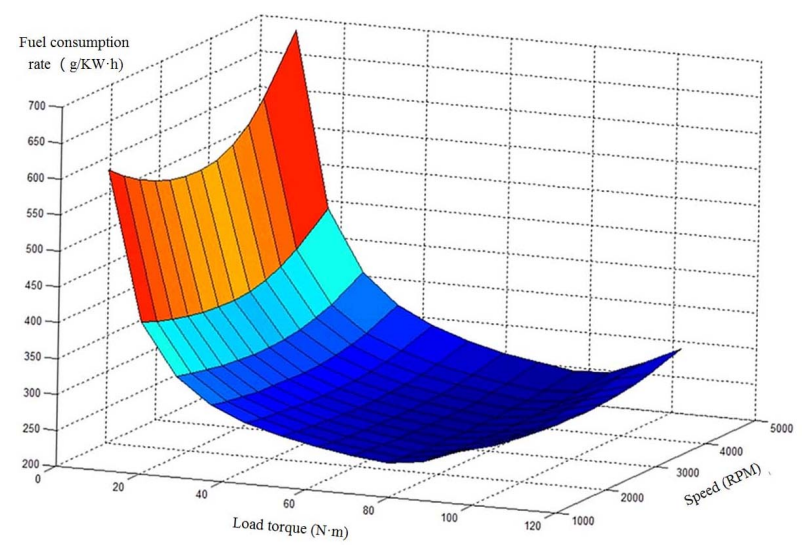

Fig. 3 Surface of the engine fuel consumption rate

$$
\begin{aligned}
\text { fuel }(x, y)= & p 1+p 2 x+p 3 y+p 4 x^{2}+p 5 x y+p 6 y^{2} \\
& +p 7 x^{3}+p 8 x^{2} y+p 9 x y^{2}+p 10 y^{3}+p 11 x^{4} \\
& +p 12 x^{3} y+p 13 x^{2} y^{2}+p 14 x y^{3}+p 15 y^{4} \\
& +p 16 x^{5}+p 17 x^{4} y+p 18 x^{3} y^{2} \\
& +p 19 x^{2} y^{3}+p 20 x y^{4}+p 21 y^{5}
\end{aligned}
$$

Where, $x$ is the load torque of engine, its unit is $\mathrm{N} \cdot \mathrm{m}, y$ is the speed of engine, its unit is RPM, fuel $(x, y)$ is the fuel consumption rate, and the fitting parameters are as follows: $p 1=1126, p 2=-63.83$, $p 3=-0.1656, p 4=2.051, p 5=5.5131 \mathrm{e}-3, p 6=4.84 \mathrm{e}-5, p 7=-3.371 \mathrm{e}-2, p 8=-7.607 \mathrm{e}-5, p 9=-8.099 \mathrm{e}-7$, $p 10=-1.221 \mathrm{e}-8, p 11=2.745 \mathrm{e}-4, p 12=1.657 \mathrm{e}-7, p 13=1.515 \mathrm{e}-8, p 14=-4.063 \mathrm{e}-11, p 15=2.537 \mathrm{e}-12$, $p 16=-8.682 \mathrm{e}-7, p 17=1.618 \mathrm{e}-9, p 18=-9.128 \mathrm{e}-11, p 19=5.799 \mathrm{e}-13, p 20=-4.351 \mathrm{e}-15, p 21=-1.532 \mathrm{e}-16$.

In order to get the minimum of fuel $(x, y)$, we need to solve the formula (2).

$$
\left\{\begin{array}{l}
x=T, T \in\left[T_{\min }, T_{\max }\right] \\
\forall y \in\left[Y_{\min }, \quad Y_{\max }\right] \\
\text { fuel }_{\text {opt }}=\min [\operatorname{fuel}(x, y)]
\end{array}\right.
$$

where, $T$ is the load torque of engine, it is equal to the electromagnetic torque of the inner motor, fuelopt is the fuel consumption rate of the optimal operation point. Using the steepest descent method $[5,6]$, and after several times iterative computations, we get the load torque and the speed of the optimal operation point, which are $75.5 \mathrm{~N} \cdot \mathrm{m}$ and $2990 \mathrm{RPM}$. At this working point, the fuel consumption rate is $229.78 \mathrm{~g} / \mathrm{KW} \cdot \mathrm{h}$.

\section{Control Method Design}

In the DRM-PCS, when the electromagnetic Synchronizer doesn't work, only load of engine is the electromagnetic torque from the inner motor. So in order to make the engine working at the optimal operation point, we must control the speed and torque of the inner motor is necessary

According to the structural characteristics of the DRM-PCS, the relationship between the engine speed and the inner motor speed can be expressed as:

$$
n_{e}-n_{\text {motor-in }}=\frac{V}{2 \pi r i_{0}}=n_{d}
$$

Here, $n_{e}$ is the engine speed, $n_{\text {motot }- \text { in }}$ is the inner motor speed, $n_{d}$ is the input shaft speed of the drive axle, $r$ is the effective radius of wheel, $i_{0}$ is the final drive ratio. 
Then, we design the control flow of optimal operation point control for engine, which is shown in Figure 4. And we select the two-dimensional fuzzy control method $[7,8,9]$ to control the engine. The fuzzy control flow is designed as shown in Figure 5, and the control rules as shown in Table 1.
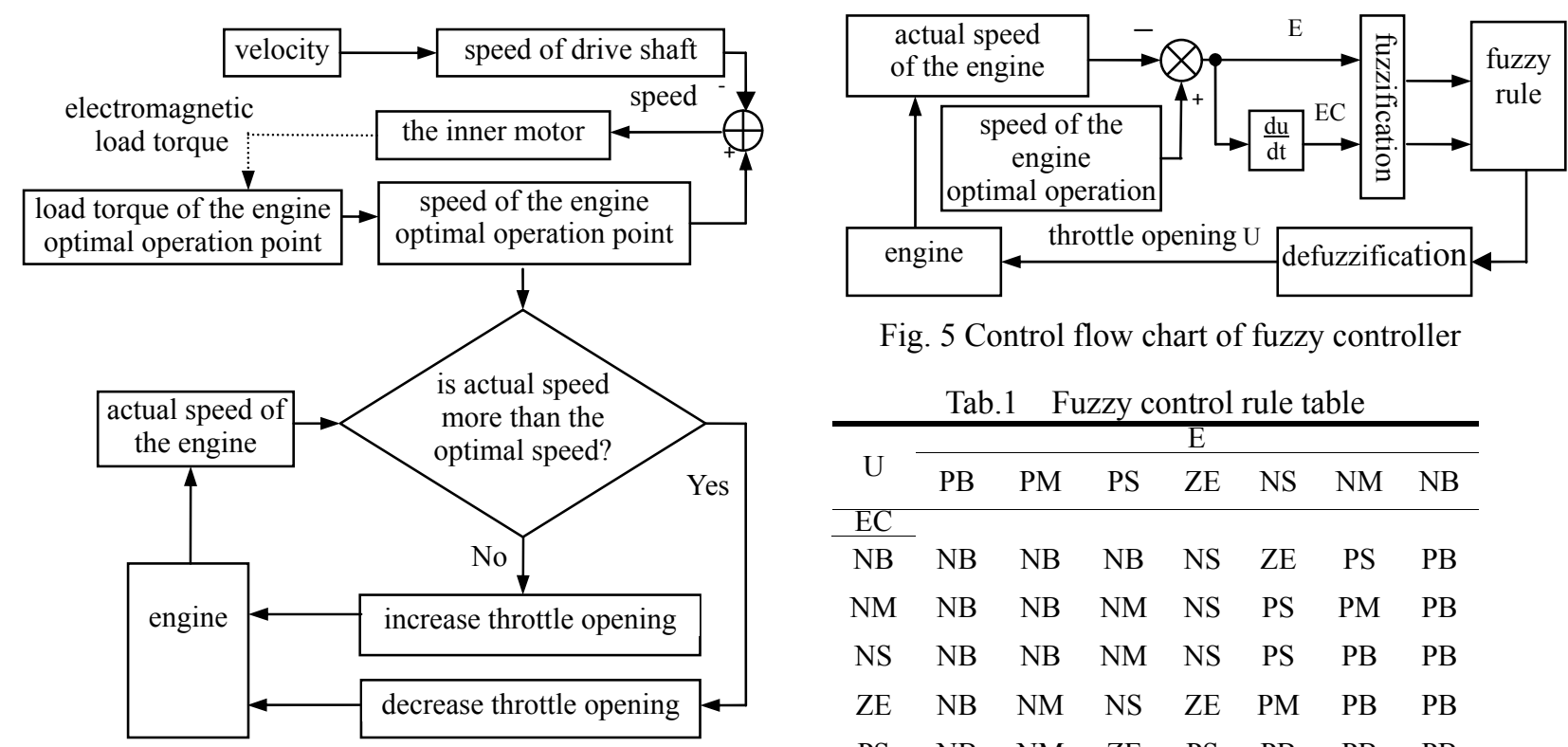

Fig. 5 Control flow chart of fuzzy controller

\begin{tabular}{|c|c|c|c|c|c|c|c|}
\hline \multirow{2}{*}{$\mathrm{U}$} & \multicolumn{7}{|c|}{$E$} \\
\hline & PB & PM & PS & ZE & NS & $\mathrm{NM}$ & NB \\
\hline $\mathrm{EC}$ & & & & & & & \\
\hline NB & NB & NB & NB & NS & ZE & PS & PB \\
\hline $\mathrm{NM}$ & NB & NB & NM & NS & PS & $\mathrm{PM}$ & PB \\
\hline NS & NB & NB & $\mathrm{NM}$ & NS & PS & PB & PB \\
\hline $\mathrm{ZE}$ & NB & $\mathrm{NM}$ & NS & $\mathrm{ZE}$ & PM & PB & PB \\
\hline PS & NB & $\mathrm{NM}$ & $\mathrm{ZE}$ & PS & PB & PB & PB \\
\hline PM & $\mathrm{NM}$ & NS & ZE & PS & PB & PB & PB \\
\hline PB & NM & NS & ZE & PS & PB & PB & PB \\
\hline
\end{tabular}

\section{Test and Analysis}

According to Figure 6, we build the hardware-in-the-loop simulation system using Matlab/ Simulink software[10] and AD5435. In the simulation system, the inner motor and the outer motor are simulated by permanent magnet synchronous motor model, and are controlled by SVPWM vector control method[11,12]. The parameters of vehicle model is set by the reference of Toyota Prius car, and the lap time of the simulation system is set to $0.5 \mathrm{~s}$.

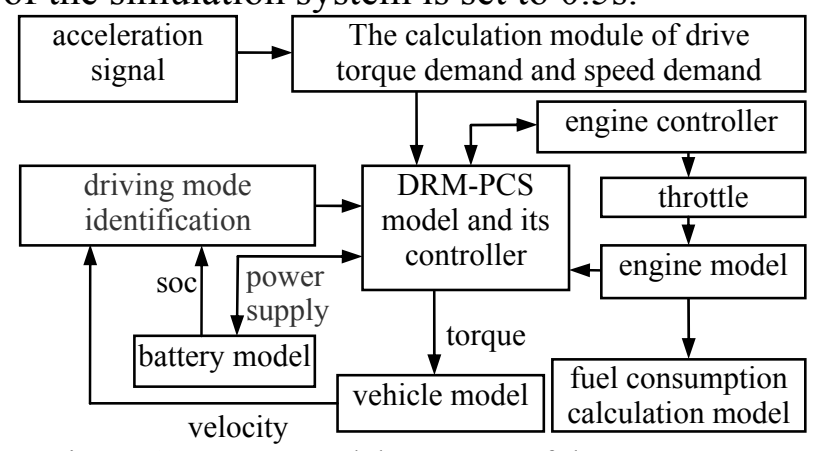

Fig. 6 Simulation model structure of the DRM-PCM

In order to prove the performance of the optimal operation point control method, this paper simulates the other two control methods: switch control method(open the engine throttle to $100 \%$ rapidly), and NECS control method ${ }^{[13]}$. Though the performance comparison, we can find the merits and demerits of the optimal operation point control method. The simulation results are show in Figure 7-12. 


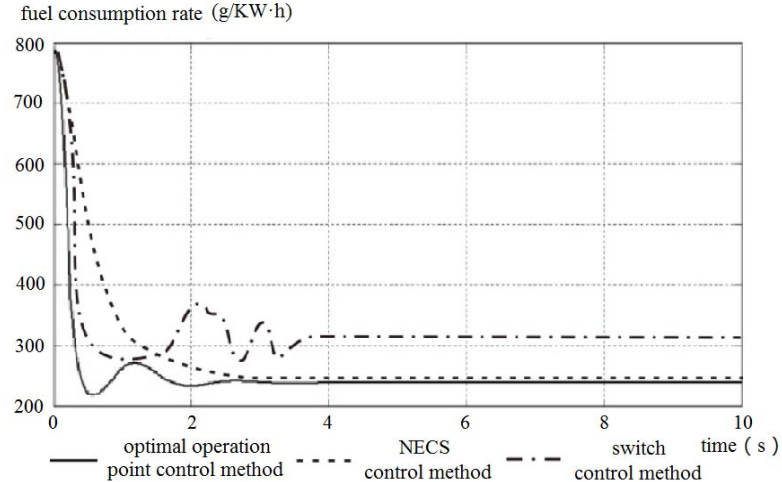

Fig. 7 Engine fuel consumption rate curve in parking generation mode

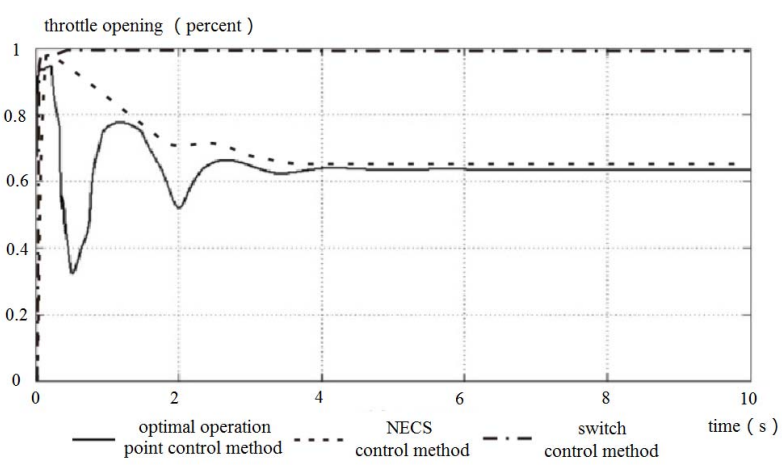

Fig. 9Throttle opening curve in parking and generation mode

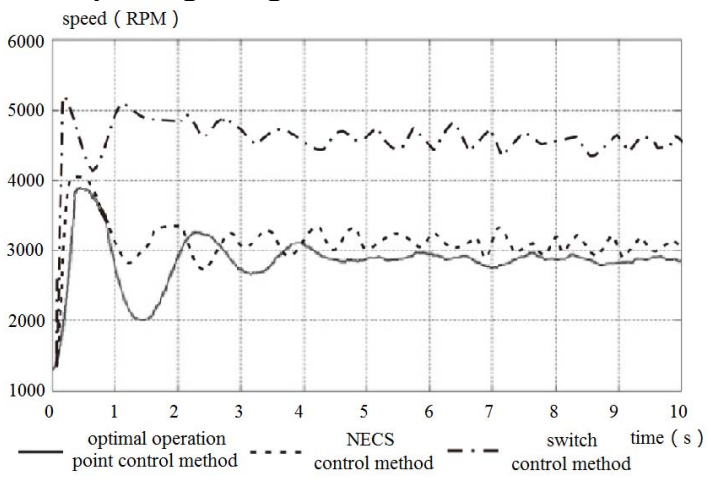

Fig. 11 Engine speed curve

in hybrid drive mode with low speed

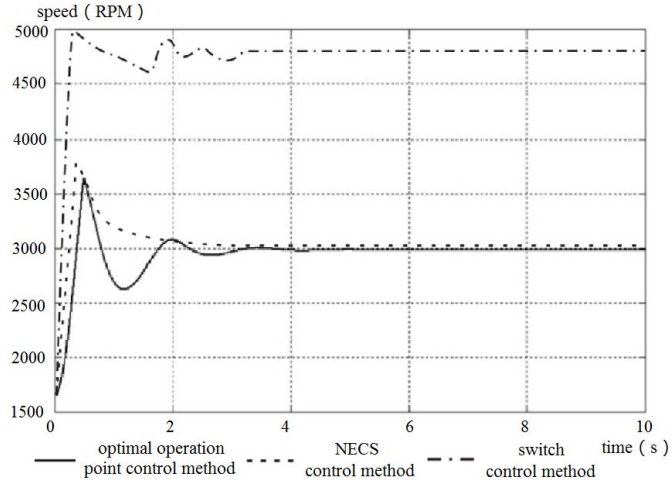

Fig. 8 Engine speed curve in parking generation mode

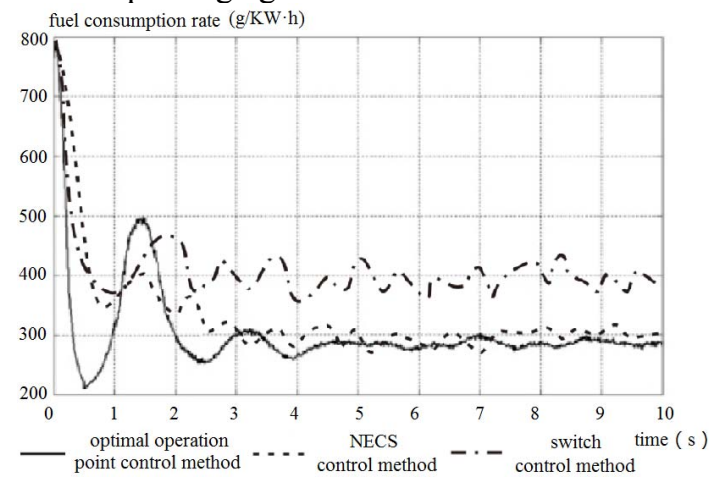

Fig. 10 Engine fuel consumption curve in hybrid drive mode with low speed

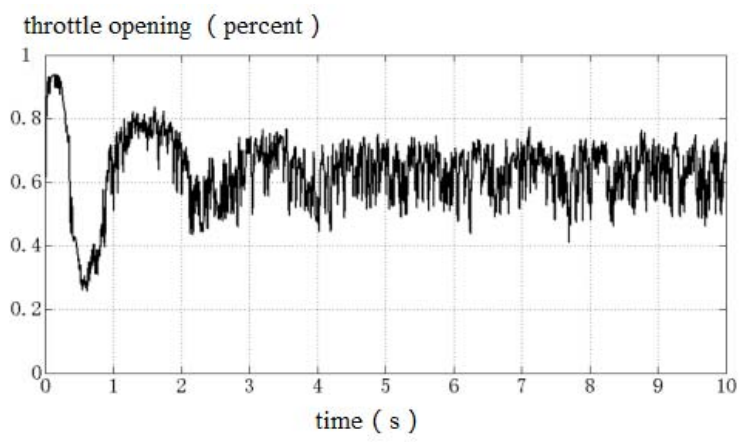

Fig. 12 Throttle opening curve in hybrid drive mode with low speed under the optimal operation point control

Analyzing Figure 7-9, we can know the engine must be controlled effectively in the parking generation mode. Using switch control method, the fuel consumption rate can up to $310 \mathrm{~g} / \mathrm{KW} \cdot \mathrm{h}$, and the stable speed of engine can be up to 4810RPM. We can also know that the optimal operation point control of engine has achieved the intended target, and can search the minimum of engine fuel consumption rate. With the optimal operation point control, the engine fuel consumption rate can stabilize at $237.9 \mathrm{~g} / \mathrm{KW} \cdot \mathrm{h}$ after about $3.8 \mathrm{~s}$ from simulation start, which is slightly larger than the optimal value. The speed of engine fluctuates slightly between 2980RPM and 2995RPM after about $3.4 \mathrm{~s}$, and the stable value of engine throttle angle is about $63.5 \%$.

In addition, from Figure 7-9, we still can see that NECS control method is much better than switch control. But compared with the optimal operation point control, the convergences of fuel consumption rate and the engine speed are slower, and the minimum values after convergence are bigger. In author' opinion, the main reason is the method difference of search the optimal point. the optimal operation point control searches the working point by fitting the curved surface of fuel consumption rate with higher power, and can get the better accuracy.

From Figure 10, we can see the fuel consumption rates of three control methods are fluctuating obviously and the fuel consumption rates are higher than in parking generation mode. we analyze the reason and believe the main reason is that the change of demand drive power when speed 
demand of driver increases. This change can lead to the fluctuation of the engine load, and can eventuate in the fluctuation of the fuel consumption rate indirectly.

Furthermore, analyze the Figure 10, we can know that the optimal operation point control method still has the best performance, and the mid-value of the fuel consumption rate is $279.3 \mathrm{~g} / \mathrm{kW} \cdot \mathrm{h}$ when the situation becomes stable. This data only exceeds the optimal number by $49.52 \mathrm{~g} / \mathrm{kW} \cdot \mathrm{h}$, and lets us think the optimal operation point control method can find the optimal operation point of engine, and work well in this mode.

In Figure 11, three control methods all have certain fluctuations. The speed mid - value of the optimal operation point control method is about 2840RPM, and the speed mid - value of NECS method is about 3130RPM, and the data of switch control is bigger than 4700 RPM. Therefore, we can confirm the optimal operation point control method has the best effect.

In the Figure 12, the situation is similar, the throttle angle under the optimal operation point control fluctuates obviously. The reason is as follow: the drive torque is adjusted by the outer motor mainly, and it has no direct link to the inner motor, but the outer motor and the inner motor share the outer rotor in the DRM-PCS, this structure can't avoid the transmission of velocity wave motion to the inner motor. As the result, the velocity wave motion makes the engine speed optimization process difficult, and the optimization time is spun out. This problem has been the next research topic of us.

\section{Conclusions}

DRM-PCS is a typical representative of the electromagnetic power coupling system. In this system, the engine' operation is unaffected by the wheel load, and the working efficiency can be kept at higher value. Based on the structure characteristics of DRM-PCS, this paper puts forward the method and the think of the optimal operation point control. Then according to the universal performance characteristic map and using data fitting, we get the mathematical model of engine fuel consumption characteristic. By the steepest descent method, we calculate the optimal operation point of engine. In order to validate the validity of the the optimal operation point control method, we build the hardware-in-the -loop simulation system in Matlab/Simulink software, and simulate the operation process of the parking generation mode and hybrid drive mode ( in low speed ). The simulation results show that: the optimal operation point control method can control the engine effectively in the DRM-PCS, and compared with switch control method and NECS control method, the optimal operation point control method has the certain advantages in engine fuel consumption rate and on the control of engine speed. Of course, for the optimal operation point control method, there is still some room to improve. The following work is shortening the optimal time and enhancing the sensitivity of the optimal operation point control method.

\section{Acknowledgment}

This work is supported by the Post-graduate Innovative Fund Project of Jiangsu Province (CXZZ13_0661), the Jiangsu Province Key Laboratory of Automotive Engineering (QC201301), the Natural Science Foundation of the Jiangsu Higher Education Institutions of China (13KJB580004, 13KJB580005,14KJD580003).

\section{References}

[1]Hoeijmakers M. J \& Rondel M, The Electrical Variable Transmission in a City Bus. 35th IEEE Power Electronics Specialist Conference, Aachen, Germany, pp.2273-2278, 2004.

[2]Shi Guangkui, Zhao Hang \& Feng Qi. A Study on Hybrid PowerSystem with Double RotorMotor. Automotive Engineering, 29(2), pp.97-100, 2007. (in Chinese with English abstract)

[3]Mo Lihong, Quan Li \& Zhu Xiaoyong, An overview of dual-rotor motor and its application to hybrid electric vehicle. Engineering Journal of Wuhan University, 45(4), pp.510-515,2012. (in 
Chinese with English abstract)

[4] Li Zhong, Jin Xiaogang \& Ma Lizhuang, Construction of Polynomial Blending Curves and Surfaces. Journal of computer-aided Design \& Computer Graphics, pp.8-13, 2011(1). (in Chinese with English abstract)

[5] Li Hongyi, Idealized Steepest Descent Method and Its Approximate Example. Journal of Shanghai Second Polytechic Unversity, pp.8-13,2011(1). (in Chinese with English abstract)

[6] Ma Yanqin, Dai Sufen \& ZHANG Bind. The Unconstrained Optimization Global Convergence Algorithm. Journal of Chongqing University of Technology( Natural Science), 1(10), pp.120-122+126,2012. (in Chinese with English abstract)

[7]Shi Xinmin, Dai Sufen \& Zhang Bing, Fuzzy Control and MATLAB Simulation, Beijing Jiaotong University press, Beijing, 2008.

[8] Bai Yuqing, Sun Yunshan \& Zhang Liyi. The Selecting Method of Fuzzy Subordinate Function in the Signal Treatment. Sci-Tech Information Development \& Economy, 2 (21), pp.254-255,2006.

[9]Wang Zhenglin, MATLAB/Simulink and Simulation of Control System (the Third Edition), Publishing House of electronics industry: Beijing, 2012.

[10]Tan Zhi \& Yuan Lili, Simulation Analysis in SVPWM Vector Control for Permanent Magnet Synchronous Machine. Instrumentation . Analysis . Monitoring, 1(4), pp.22-24,2009. (in Chinese with English abstract)

[11] Qiu chen, Research on the SVPWM vector control algorithm of permanent magnet synchronous motor based on DSP. Electrician Abstracts, 1(4), pp.36-38, 2012. (in Chinese with English abstract)

[12] Wang Feng, Zhong Hu \& Ma Cilin, Simulation Study on Engine Operation control for Electromagnetic Coupling Hybrid Electric Vehicles. Chinese High Technology Letters, 18(11), pp.1200-1205, 2008. (in Chinese with English abstract) 